\title{
Editorial: The social and enactive mind
}

\author{
Ezequiel Di Paolo
}

Published online: 25 August 2009

(C) Springer Science + Business Media B.V. 2009

\begin{abstract}
There is no zero-point of the social relatedness of the individual, no "beginning" or sharp break when he steps into society as if from outside as a being untouched by the network and then begins to link up with other human beings. On the contrary, just as parents are needed to bring a child into the world, just as the mother feeds the child first with her blood and then with nourishment from her body, the individual already exists, on the most fundamental level, in relation to others, and this relation has a particular structure specific to his society. He takes on his individual stamp from the history of these relationships, these dependences, and so, in a broader context, from the history of the whole human network within which he grows up and lives. [...] Robinson Crusoe, too, bears the imprint of a particular society, a particular nation and class. Isolated from all relations to them as he is on his island, he behaves, wishes and plans by their standard...
\end{abstract}

Norbert Elias (1939/1991), p.27

As alternatives to the dominant computationalist approach to cognition develop toward scientific maturity, the taken-for-granted departure and end points of mind science begin to be questioned more systematically. The simple and apparently given starting points are often revealed as presupposing the more complex stages that are relegated to longer term explanatory goals. Similarly, the apparently complex feat is sometimes shown to be simpler to explain and more basic once certain methodological and conceptual blinders are removed. We witness this pattern in various regions of cognitive science, for instance, over the last two decades, in the

E. Di Paolo $(\bowtie)$

Centre for Research in Cognitive Sciences, Centre for Computational Neuroscience and Robotics,

School of Informatics, University of Sussex, Brighton BN19QH, UK

e-mail: ezequiel@sussex.ac.uk 
embodied turn in artificial intelligence and robotics, the emerging field of cognitive linguistics and in embodied and dynamical accounts of action and perception.

In social cognition research a comparable pattern is taking shape. This field, until now poorly defined in circular ways ("the study of information processing in a social setting", Frith 2008, p. 2033, or "the cognitive processes used to decode and encode the social world", Beer and Ochsner 2006, p. 98) is currently the target of a phenomenologically informed and theoretically loaded re-think.

One key issue exemplifies the situation: the status of social interaction in explanations of social cognition. Traditionally, perception has been seen as dissociated from action and, in the linear order of things, as prior to it. This partly explains the overarching emphasis in social cognition research on the perception of the social world (despite advances that challenge this assumption in other areas of cognitive science). According to the unspoken presupposition, first we must get a grip on social perception in order to then proceed to social action and this will put us in a situation to finally understand the interaction domain. In this picture, even when engaged in the liveliest interaction, say, a jam session, a social agent takes a number of micro-pauses so as to become detached from the flow of mutual activity and run (very quickly) a series of private computations (inferences, simulations, take your pick), in order to plan and execute the next move. At that point time unfreezes until the next micro-pause. Needless to say, in this view, an interaction is the sum total of individual actions without remainder. The 'social' in social cognition is merely contextual.

When the ideas of the enactive approach to life and mind (Varela et al. 1991; Thompson 2007) are applied to social cognition, this picture is turned on its head (De Jaegher and Di Paolo 2007; see also Thompson 2001, 2007). By showing how an interaction is under-determined by the sum total of individual actions and how it places demands on the interactors that do not allow for micro-pauses and often require them to act before they can think, enactivism questions the programmatic assumptions that dominate research in social cognition. Two sets of processes of individual perception, decision-making and action do not add up to a process of social interaction in this view. This means not only that some element is (and will remain) missing but also that the third-personal departure point is poorly chosen. Add to this the strong arguments showing that the very possibility for a detached stance from where a social scene can be observed and interpreted (e.g., the understanding of the remote other, the passing of false-belief tests) is likely to be the result of a history of interactive practises (heavily influenced by cultural norms) and we can begin to suspect that research in social cognition might have got off on the wrong foot. These and other points are argued for in the contributions to this special issue on the social and enactive mind.

It should be noted that a myriad of interesting problems is contained within the domain of social interaction: e.g., joint action, making meaning together, conversations, education, participation in communal activities, group dynamics, therapeutic relations, friendship, narratives, family processes, the experience of connectedness, conflict resolution, relations in the work-place, disagreements, regulation of personal space, anonymous interactions, prejudices, internalisation of social norms, community building, xenophobia, violence, involvement, submission, detachment, loneliness, trust, persuasion, respect, obedience, power, love, helping 
and giving thanks. To assume that the third-personal understanding of others is prior to our capabilities to interact is also to assume that it is prior to all of these problems, a risky assumption with no clear justification.

The explicit motivation for this special issue (and the workshop that gave rise to $\mathrm{it}^{1}$ ) has not been to rehearse the well-known criticisms to computational approaches, but to develop enactivism in novel directions. The result, we hope, is a set of positive proposals and new challenges that recast the way we can think about social cognition. The proposals and challenges feed from interdisciplinary thinking spanning diverse areas in embodied cognitive science, emotion theory, dynamical approaches, phenomenology, neuroscience, developmental theory, ethics and social science. All contributions are co-authored and all contributions involve a dialogue between at least two disciplines. To some extent this was intended without being enforced and the result is a gamut of different styles of conversation.

After a helpful stage-setting introducing the reader to the main concepts in the recent enactive literature, McGann and De Jaegher propose to examine social perception as the mastery of social skills in analogy to the sensorimotor approach to perception (O'Regan and Noë 2001). The latter sees perception not as the passive gathering of ambient information, but as the mastery of lawful sensorimotor contingencies. The analogy is fruitful as a way of posing the question: what is social perception in the light of an interactive, participatory approach? The analysis, however, soon takes the authors to important and interesting differences from the strictly sensorimotor story. Yes, there are self-other contingencies that characterise social encounters, but these tend to be mostly in the domain of values, intentions and affects, and moreover, they are reciprocal, and they are often negotiated during the encounter itself. They arise from interlocking bodily, interactive and cultural processes and unlike most cases of object perception they are protean in character. The social skills that must be mastered for social perception are the skills of coping interactively with regularities that can, and often will, change unexpectedly. According to McGann and De Jaegher, "social skill itself is ... a mastery of negotiation". Froese and Di Paolo, in their contribution, make a similar point in terms of a second-order transcendence: "others lend themselves to unending exploration of different styles of unending exploration". The proposal leaves the authors facing towards the role of cultural processes in instituting different ways in which we master social skills (and in so doing, crystallise different possible forms of selves). The continuity between life and mind carries a momentum into the social and cultural world with a promised "coherence that is both scientifically and humanistically satisfying".

Froese and Di Paolo latch on to this potential continuity and explore the role of sociality in re-casting what looks like a problem for embodied approaches to cognition: that of a cognitive gap between the sensorimotor level of adaptive coping and higher mental capabilities. They begin by noticing an implication of the operational definition of participatory sense-making (De Jaegher and Di Paolo 2007). Our cognition may be affected and modulated by social encounters, but as far

\footnotetext{
1 "Enactive Approaches to Social Cognition”, Battle, UK, Aug. 30-Sep. 1, 2008. This workshop was coorganised by Hanne De Jaegher, Ezequiel Di Paolo, Tom Froese and Steve Torrance with financial support from euCognition. See: http://lifeandmind.wordpress.com/battle08/.
} 
as the definition goes, this may happen even when we are not aware of the presence of the other as an other. This is backed up by experimental and modelling work and, incidentally, this property supports a recent distinction introduced by Gallagher between two related problems of intersubjectivity (2009): a problem of making sense with others and a problem of making sense of others. This implication begs further questions for the enactive approach, namely at what point does the participatory regulation of individual agency lead to a recognition of another subject and what does this recognition imply for individual perceptual capabilities. In revising recent phenomenological criticisms to sensorimotor theories of visual perception, the authors clarify the role of alternative perspectives on a given object not so much as providing the possibility for apperceiving hidden profiles, but rather as a decentering of the immediate concern that an object has for an individual agent. Thus, when I regard an object in a detached manner, I can only do this because of my implicit awareness that the meaning of this object might be different for others. Alternative concerns are added up like vectors that compensate each other and the result is a nearly concern-less regard on an object as such, its geometry, physical properties and relation to other objects. This theoretical attitude is typically considered as the starting point in most theories of perception (including to some degree by the sensorimotor account). But it turns out to be in itself a higher form of cognition. It is only made possible by a history of exposure and negotiations with alternative points of views to mine.

Fuchs and De Jaegher provide further insights into the roots of such forms of decentering that arise from interactive experience. To be thrown into a social interaction is often to experience that something is happening "in-between" ourselves, and that from this displaced centre of intentions a contour emerges that (sometimes gently, other times strongly) envelops the other and me together. In their contribution, the authors describe this experience in terms of what they call mutual incorporation and link phenomenological insights with a dynamical perspective on coordination and the enactive proposal that interactions often take a life of their own. Their crisscrossing of the boundaries between scientific and phenomenological description allows them to put an even larger distance between participative and representational approaches to social cognition. In this light, they re-interpret some aspects of the early development of intersubjectivity in mother-infant dyads. For instance, following Reddy (2008), they argue that much better sense can be made of the data on newborn imitation (e.g., why are certain gestures imitated more easily than others?) from the perspective of the significance of such gestures in creating and sustaining a shared interactive process. Affects, intentions, meanings are not locked inside individual minds but are generated and transformed in this displaced sphere even, and crucially, from our earliest interactions.

How far could such a story go? The answer is, potentially, to the very core of our sense of being agents in a world. Enacting a shared social world may play a key role in understating the ontogeny of the body schema. In their contribution, Wood and Stuart build their argument for this position in a careful, phenomenologically guided analysis of recent neuroscientific studies on congenital phantom limbs. Rather than being evidence for an innate body schema that has failed to adapt to an atypical body, aplasic phantom limb experiences might be the result of a socially regulated ontogeny. Aplasics and morphologically typical adults and children share a world of 
common goals mediated by different bodily capabilities. Recent neural studies testify to the plasticity of so-called mirroring neural responses. These neural processes better match the significance of a perceived or executed action rather than its means (e.g., picking up cup with a hand or a foot). Plasticity of a mirror system suggests a potential role for social embeddedness as a source of self-other-world regularities modulating ontogeny. These regularities (which, following the other contributions, would be negotiated in interaction) can give rise to the experience of a phantom as a way for the body schema to cohere with the enacted social world. Wood and Stuart's proposal echoes Merleau-Ponty for whom the phenomenon of phantom limbs can be "understood in the perspective of being-in-the-world. What it is in us which refuses mutilation and disablement is an $I$ committed to a certain physical and inter-human world" (1962), p. 71. While he was referring to non-aplasic phantom experiences, there is no reason to think that the exact same phenomenon could not be at the root of the ontogeny of a body schema that leads to aplasic phantoms. Underlying this line of reasoning is a perspective on developmental systems that questions traditional dichotomies such as inner/outer or innate/acquired.

In contrast to these enactive views, other approaches to social cognition treat the difference between 'one' and 'two' as predominantly numerical, not qualitative. As we have seen, their implicit methodological assumption is that individual capabilities must be addressed first in order to proceed in an apparent scale of complexity towards the social cognition problems enumerated at the beginning of this introduction. It should now be apparent that this is very likely a false ordering of the problems. However, the traditional programme does not have to be replaced by an unregulated approach where all potential factors must be considered at once, leaving little clarity about fruitful research pathways. The first three contributions present very concrete proposals that already are, or can be turned into, clear scientific questions. As a complement to this, it is also important to look at what issues lie further afield. The last two contributions point in the direction of how much territory remains to be charted even for the enactive approach as currently formulated.

As the process of interaction enters the picture as having not just a contextual but also a constitutive role for social and individual cognition, the implications spill over into other areas of concern. Colombetti and Torrance explore some of these consequences for emotion theory and ethics. What are the effects of downplaying the purely individualistic focus of traditional approaches in these fields? Starting from a rejection of a separation between emotion and cognition, they make use of the concept of participatory sense-making to explore the different affective aspects of the feeling of connectedness and how these aspects link to different modes of relation and interaction. Their analysis indicates that the autonomy of interactions that is part of the concept of participatory sense-making nicely dovetails with the work by Thompson (2001, 2007) on empathy, alterity and imaginary transpositions; a discussion which itself resonates with the idea of mutual incorporation proposed by Fuchs and De Jaegher. More radically, the rejection of an emotional/rational divide also allows Colombetti and Torrance to make an incursion into the domain of ethics and give us a glimpse of what could be the consequences of participatory sensemaking for a re-appraisal of ethics. If interaction can truly take on a life of its own, the boundaries of individual responsibility become intertwined without fully 
disappearing. Not only do they extend into each other's territories (we participate in each other's actions and emotions; we influence each other's autonomies, we create meaning together), but they are also invaded by a third, relational element: the dynamical modes of the interaction process. This is beautifully illustrated in an example from two different instances of interaction in a situation of care. Different patterns of interaction can self-reinforce resulting in the sedimentation of either more 'negative' or more 'positive' emotional tonalities. They can also result in the reinforcement of autonomy-reducing or autonomy-enhancing (thus, ethical) consequences for the individual person under care. What the enactive approach suggests is that the "dance of participatory sense-making is inevitably ethical in nature".

If the concept of participatory sense-making is an attempt to place the interaction process in a central place and move beyond the individualistic, skull-bound conception of cognition (social or otherwise), the contribution by Steiner and Stewart shows us how much distance still needs to be covered in this direction. They offer and defend a radical spin on what counts as the (humanly) social, taking it not just outside the individual minds and into the interaction order, but further into the normative order that pre-exists, and at the same time constrains and enables, our human social encounters. As much as the interaction process is no mere background to two solipsistic minds second-guessing each other, the norms that regulate human encounters are themselves constitutive of our interactive and cognitive capabilities. This normative order imposes a relation of heteronomy between the individual and the social world. This relation, rather than being in contraposition to the autonomy of individuals and encounters, can provide the constraints needed for human social autonomy to thrive (take the obvious case of learning a language). Steiner and Stewart's arguments combine enactive ideas with a middle-of-the-road perspective on the co-defining relation between social structures and individual agency. They challenge - or extend - the enactive approach to social cognition. The latter remains impoverished in as much as the hetoronomy that emanates from the normative order is merely contextual and not properly thematised. To be sure, this is indeed a challenging line of thought inviting several routes for further dialogue and that will compel the enactive approach to clarify its position. We may immediately notice, as the authors do, that the autonomy of the interaction process proposed by De Jaegher and Di Paolo (2007) is in itself a form of heteronomy from the perspective of the interactors (likewise, the heteronomy of the normative order is in itself a form of autonomy of socio-cultural structures). The authors are right in that there is a difference between pre-existing (but not immutable) norms and those that emerge in a dyadic encounter, but spelling out the relation between these forms of heteronomy emerges as precisely the challenge to consider in order to-in resonance with McGann and De Jaegher-provide a satisfactory account of the relations between life, mind and society.

In summary, the constitutive role of sociality for individual cognition and experience is an explicit theme in most of the contributions: from the role of practises in self-other contingencies in the formation of social skills (McGann and De Jaegher), which may go as deep into individual agency as in the very shaping of the body schema (Wood and Stuart) to sociality as the condition for the possibility of a detached perceptual attitude in humans (Froese and Di Paolo) and the development of individual autonomy afforded by a cultural normative order (Steiner and Stewart). 
In addition, to allay fears that the enactive approach to the social mind is overly intellectualistic, most contributions, but two in particular, develop the theme of the intimacy of the social and the personal in the domain of the experiences of fascination, de-centering and mutual incorporation (Fuchs and De Jaegher) and in the implications for emotion theory and ethics (Colombetti and Torrance).

By turning its attention to the social, enactivism itself is bound to change as shown already by some of the tensions and developments in this special issue. The path is laid down in walking as the enactive motto adapted from Antonio Machado tells us. His poem speaks of a solitary walker. But the walking (and not just the talking) are participatory activities; even solitary Robinsons laying down their novel paths walk in ways that are reminiscent of paths once transited by and with others.

\section{References}

Beer, J., \& Ochsner, K. (2006). Social cognition: A multi-level analysis. Brain Research, 1079, 98-105. De Jaegher, H., \& Di Paolo, E. (2007). Participatory sense-making. An enactive approach to social cognition. Phenomenology and the Cognitive Sciences, 6, 485-507.

Elias, N. (1939/1991). The society of individuals. trans. by Edmund Jephcott. Oxford: Basil Blackwell.

Frith, C. (2008). Social cognition. Philosophical Transactions of the Royal Society B, 363, 2033-2039.

Gallagher, S. (2009). Two problems of intersubjectivity. Journal of Consciousness Studies, 16, 289-308.

Merleau-Ponty, M. (1962). Phenomenology of perception, trans. by Colin Smith. London: Routledge.

O'Regan, J. K., \& Noë, A. (2001). A sensorimotor account of vision and visual consciousness. Behavioral and Brain Sciences, 24(5), 883-917.

Reddy, V. (2008). How infants know minds. Cambridge: Harvard University Press.

Thompson, E. (2001). Empathy and consciousness. Journal of Consciousness Studies, 8, 1-32.

Thompson, E. (2007). Mind in life: Biology, phenomenology, and the sciences of mind. Cambridge: Harvard University Press.

Varela, F. J., Thompson, E., \& Rosch, E. (1991). The embodied mind: Cognitive science and human experience. Cambridge: MIT Press. 